\title{
Predictive Validity of ICD-11 PTSD as Measured by the Impact of Event Scale-Revised: A 15-Year Prospective Study of Political Prisoners
}

\author{
Philip Hyland, ${ }^{1,2}$ Chris R. Brewin, ${ }^{3}$ and Andreas Maercker ${ }^{4}$ \\ ${ }^{1}$ School of Business, National College of Ireland, Dublin, Ireland \\ ${ }^{2}$ Centre for Global Health, School of Psychology, Trinity College Dublin, Dublin, Ireland \\ ${ }^{3}$ Clinical, Educational, and Health Psychology, University College London, London, England \\ ${ }^{4}$ Department of Psychology, Division of Psychopathology, University of Zurich, Zurich, Switzerland
}

\begin{abstract}
The $11^{\text {th }}$ edition of the International Classification of Diseases (ICD-11; World Health Organization, 2017) proposes a model of posttraumatic stress disorder (PTSD) that includes 6 symptoms. This study assessed the ability of a classification-independent measure of posttraumatic stress symptoms, the Impact of Event Scale-Revised (Weiss \& Marmar, 1996), to capture the ICD-11 model of PTSD. The current study also provided the first assessment of the predictive validity of $I C D-11$ PTSD. Former East German political prisoners were assessed in $1994(N=144)$ and in 2008-2009 $(N=88)$ on numerous psychological variables using self-report measures. Of the participants, $48.2 \%$ and $36.8 \%$ met probable diagnosis for ICD-11 PTSD at the first and second assessments, respectively. Confirmatory factor analysis supported the factorial validity of the 3-factor ICD-11 model of PTSD, as represented by items selected from the Impact of Event Scale-Revised. Hierarchical multiple regression analysis demonstrated that, controlling for sex, the symptom clusters of ICD-11 PTSD (reexperiencing, avoidance, and sense of threat) significantly contributed to the explanation of depression $\left(R^{2}=.17\right)$, quality of life $\left(R^{2}=\right.$ $.21)$, internalized anger $\left(R^{2}=.10\right)$, externalized anger $\left(R^{2}=.12\right)$, hatred of perpetrators $\left(R^{2}=.15\right)$, dysfunctional disclosure $\left(R^{2}=.27\right)$, and social acknowledgment as a victim $\left(R^{2}=.12\right)$ across the 15 -year study period. Current findings add support for the factorial and predictive validity of $I C D-11$ PTSD within a unique cohort of political prisoners.
\end{abstract}

The forthcoming revision of the International Classification of Diseases into its $11^{\text {th }}$ version by the World Health Organization (ICD-11; WHO, 2017) involves a new concept of posttraumatic stress disorder (PTSD) that essentially is a narrower description compared to previous PTSD definitions. Based on a variety of research designs including dimensional modeling of PTSD symptoms, ICD-11 PTSD is defined by three core elements: reexperiencing of the traumatic event in the present, avoidance of thoughts and behaviors related to the trauma, and an ongoing sense of threat (Brewin, Lanius, Novac, Schnyder, \& Galea, 2009; Maercker, Brewin, et al., 2013). The current report concerns an investigation of whether items from an existing, widely used measure of posttraumatic stress, the Impact of Event Scale-Revised (IES-R; Weiss \& Marmar, 1996) can be used to model the $I C D-11$ description of PTSD, and additionally

Correspondence concerning this article should be addressed to Philip Hyland, School of Business, National College of Ireland, IFSC, Mayor Street, Dublin 1, Ireland. E-mail: Philip.hyland@ ncirl.ie

Copyright (c) 2017 International Society for Traumatic Stress Studies. View this article online at wileyonlinelibrary.com

DOI: $10.1002 /$ jts.22171 whether scores generated from this scale can predict a range of outcomes over a 15 -year study period.

The ICD-11 principles involve simplifying disorders wherever possible to improve their recognizability and clinical utility worldwide (First, Reed, Hyman, \& Saxena, 2015). In the proposals for PTSD, there will be six (or seven, if a respondent indicates that they possess no clear memory of the traumatic event) symptoms included in the diagnosis; a substantial reduction in the number of symptoms included as compared to the ICD-10 and the fifth edition of the Diagnostic and Statistical Manual of Mental Disorders (DSM-5; American Psychiatric Association, 2013). To meet the diagnostic criteria for PTSD, the $I C D$ - 11 requires exposure to a traumatic event of a threatening or horrific nature, the combination of one of two reexperiencing symptoms (one of three should an individual indicate no clear memory of the trauma), one of two avoidance symptoms, and one of two sense of threat symptoms (Table 1). In a further revision to the $I C D-10$ criteria, symptoms must be present for several weeks, and there must be evidence of functional impairment associated with these symptoms. Emerging evidence indicates that the 3 -factor structure fits the data very well, although in some samples other models are also viable (Forbes et al., 2015; Gluck, Knefel, Tran, \& Lueger-Schuster, 2016; 
Table 1

Item Mapping for ICD-11 PTSD Using the IES-R

\begin{tabular}{lll}
\hline ICD-11 Symptoms of PTSD & IES-R Items & \multicolumn{1}{c}{ Description } \\
\hline Upsetting dreams of the trauma & IES-R 20 & I had dreams about (the trauma). \\
Reliving the trauma & IES-R 9 & Pictures about (the trauma) popped into my mind. \\
Avoidance of internal reminders & IES-R 11 & I tried not to think about (the trauma). \\
Avoidance of external reminders & IES-R 8 & I stayed away from reminders of (the trauma). \\
Hypervigilance & IES-R 21 & I felt watchful and on-guard. \\
Exaggerated startle response & IES-R 10 & I was jumpy and easily startled.
\end{tabular}

Note. ICD-11 = International Classification of Diseases, $11^{\text {th }}$ edition.; IES-R $=$ Impact of Event Scale-Revised.

Hansen, Hyland, Armour, Elklit, \& Shevlin, 2015; Haravuori, Kiviruusu, Suomalainen, \& Marttunen, 2016; Tay, Rees, Chen, Kareth, \& Silove, 2015). Moreover, in direct comparisons the ICD-11 structure has been shown to fit the data better than DSM-based models (Hansen et al., 2015; Tay et al., 2015). There is preliminary evidence that prevalence under $I C D-11$ is lower than it is under $I C D-10$, probably due to the requirement for evidence of functional impairment, and that comorbidity with depression is reduced relative to $D S M$-based diagnoses (Morina, van Emmerik, Andrews, \& Brewin, 2014; Stammel, Abbing, Heeke, \& Knaevelsrud, 2015).

Changing PTSD definitions and criteria have been bemoaned by clinicians and researchers (e.g., Bisson, 2013) because they may create transition problems from the previous to the new version. As an alternative to designing new instruments, it may be possible to estimate who meets the new criteria by using disorder assessments that are independent of particular classification versions. Based on Horowitz's (1976) pioneering work on stress-response syndromes, the IES-R (Weiss \& Marmar, 1996) is such a generic measure of PTSD, largely independent of succeeding versions of the $D S M$ or $I C D$, and measuring symptom severity instead of frequency. The IES-R has been widely used in assessing PTSD in diverse settings around the world (e.g., Herberman Mash, Ursano, Benevides, \& Fullerton, 2016; Thormar et al., 2016), and therefore may be applicable to researching even the recent $I C D-11$ PTSD definition with its narrowed-down approach to diagnosis.

A longitudinal study on traumatized political prisoners from the former East German communist country (German Democratic Republic, 1949-1990) provides an opportunity to investigate the symptom structure and predictive validity of $I C D-11$ PTSD estimated from items of the IES-R, mapped over a 15year interval. We predicted that confirmatory factor analysis (CFA) on the selected items would support the 3-factor structure proposed for $I C D-11$ (reexperiencing, avoidance, and sense of threat). In addition, the dataset allows for the prospective prediction of a broader range of PTSD-related outcomes. Based on the well-established relationships between depression (e.g., Stander, Thomsen, \& Highfill-McRoy, 2014) and quality of life (e.g., Schnurr \& Lunney, 2016), respectively, and PTSD symptomatology, we hypothesized that ICD-11 PTSD would be a robust predictor of both of these outcome variables. In addition to these traditionally studied correlates of PTSD, the current study focused on two important sets of outcomes for trauma victims that are understudied (see Maercker \& Horn, 2013): PTSD-relevant social affects (anger, and hatred towards perpetrators) and interpersonal consequences (dysfunctional disclosure experiences, and perceived social acknowledgment as a victim). Based on data indicating that $I C D-11$ PTSD, with its refined symptom set focusing on symptoms relating to emotions of fear and horror, is associated with reduced levels of PTSD-relevant social affective responses such as aggression (e.g., Hansen et al., 2015), we predicted that $I C D-11$ PTSD would be a stronger predictor of the interpersonal outcome variables than of the social affective outcome variables.

\section{Method}

\section{Participants and Procedures}

This study used longitudinal data from a sample of former East German political prisoners (Maercker, Gäbler, O'Neil, Schützwohl, \& Müller, 2013). The sample was first investigated in 1994 (Time 1 [T1]; $N=144$ ), 5 years after the fall of the communist regime and the shutdown of political prisons, and again in 2008-2009 (Time 2 [T2]; $N=91$ ). $\mathrm{T} 1$ interviews were conducted approximately 24 years $(M=$ $23.60, S D=10.70)$ after their release from prison. The participation rate at follow-up was $63.2 \%$ due to mortality, refusal to participate, or inability to locate the respondent. Interviews were conducted at a university hospital in Dresden, Germany, or if participants were unable to travel, in their hometowns. Ethical approval for the project was granted by the Ethics Review Board of the University of Zurich, Switzerland.

Among those assessed at T1, 85.4\% $(n=123)$ were male, and most were married $(58.6 \%, n=82)$. The mean age was 53.60 years $(S D=11.90)$, and the mean duration of imprisonment was 36.30 months $(S D=37.20)$. Many individuals were employed $(32.6 \%, n=45)$, receiving state pension $(39.9 \%, n=$ $55)$, or unemployed $(22.5 \%, n=31)$, with the remainder either employed part-time $(2.9 \%, n=4)$, or receiving education $(1.4 \%, n=2)$. Of those available for follow-up, $83.5 \%$ were male $(n=76)$, and the majority were married $(58.6 \%, n=51)$. The mean age was 64.40 years (range $=40$ to 85 years), and 
individuals had a mean of 30.00 months $(S D=29.20)$ duration of imprisonment. More details of the sample demographics and study procedures are given in Maercker, Gabler, et al. (2013), who reported that only older age and lower education were associated with sample attrition between $\mathrm{T} 1$ and $\mathrm{T} 2$.

\section{Measures}

ICD-11 PSTD symptoms. The Impact of Event ScaleRevised (Weiss \& Marmar, 1996; German version: Maercker \& Schützwohl, 1998) includes 22 items measuring symptom severity in the domains of intrusions, avoidance, and hyperarousal during the last 7 days. Symptoms are measured on a 4-point Likert scale $(1=$ not at all, $2=$ rarely, $3=$ sometimes, and $4=$ often; the German version uses the 4-point scaling of the original IES and thus differs from the English version of the IES-R). It was applied with reference to the index trauma of political imprisonment. Six IES-R items were selected to map the ICD-11 PTSD definition (Table 1). The six items reflected the symptoms provided by First et al. (2015) for $I C D-11$ PTSD. To estimate probable $I C D$ - 11 PTSD diagnosis, the six items were dichotomized to indicate the presence or absence of a given symptom. According to standard conventions for determining symptom presence based on self-report, Likert scale measurements were followed (e.g., Elklit \& Shevlin, 2007), whereby a score of 3 or greater was used to indicate symptom presence. Functional impairment associated with PTSD symptoms was not measured at T1 (1994), but was included at T2 (2008-2009) as part of the clinician-administered Diagnostic Interview for Psychological Disorders (Schneider \& Margraf, 2006). Accordingly, estimates of probable ICD-11 PTSD diagnoses at $\mathrm{T} 1$ were based on symptom criteria requirements, whereas at T2, diagnostic estimates were estimated using symptom criteria alone, and with the use of the functional impairment criteria. The internal reliability (Cronbach's $\alpha)$ of the six items of the IES-R was satisfactory at T1 $(\alpha=.82)$ and T2 $(\alpha=.84)$.

Mental health. The Beck Depression Inventory (Beck, Steer, \& Carbin, 1988) is a well-established 21-item self-report instrument for assessing depression severity. Each item is measured along a 4-point Likert scale (0-3), with higher scores indicating greater levels of depressive symptomatology. The scale possessed satisfactory internal reliability $(\alpha=.93)$.

The WHO-5 assesses quality of life with five items related to well-being (Bech, 2004). The scale developed by WHO has been globally validated and shows good psychometric features (Topp, Østergaard, Søndergaard, \& Bech, 2015). The reliability was satisfactory among the current sample $(\alpha=.86)$.

Social affect. The State-Trait-Anger-Expression Inventory (STAXI; Spielberger, 1988) is a 45-item self-report measure assessing the extent of anger and its expression (externalized and internalized anger). The internalized scale measures the extent to which feelings of anger are withheld, and the externalized scale measures the extent to which feelings of anger are expressed outwardly. The psychometric properties of the German translation of the STAXI have been previously demonstrated (Schwenkmezger, Hodapp, \& Spielberger, 1992). Reliability of the full scale $(\alpha=.90)$ and the internalizing subscale $(\alpha=.75)$ were satisfactory, although reliability of the externalizing subscales was somewhat low $(\alpha=.61)$.

Hatred towards perpetrators was measured via three items (e.g., "Do you feel hatred about what has happened to you during the imprisonment?") previously used by Lopes Cardozo, Kaiser, Gotway, and Agani (2003). The items assess degrees of hatred and revenge feelings, fantasies, or intentions on a 3-point scale (not at all to extremely). The scale possesses satisfactory psychometric properties (Orth, Maercker, \& Montada, 2003) and the original reference to hatred towards war was replaced with a reference to political imprisonment. The reliability of the three items among the current sample was satisfactory $(\alpha=.86)$.

Interpersonal consequences. The Dysfunctional Disclosure Questionnaire (DDQ; Müller \& Maercker, 2006) covers in three subscales the reluctance to talk, the urge to talk, and emotional reactions during disclosure. The DDQ includes 12 items and each item is assessed using a 6-point Likert scale. The scale has demonstrated sufficient psychometric properties (Müller, Moergeli, \& Maercker, 2008). The reliability of the DDQ in the current sample was satisfactory $(\alpha=.80)$.

The Social Acknowledgement Questionnaire (SAQ; Maercker \& Müller, 2004) measures individuals' perception of being recognized as a victim or survivor, and the perceived support from one's societal milieu. The SAQ contains 16 items, each measured using a Likert scale from $1=$ not at all to $3=$ completely. The SAQ possesses sufficient psychometric features (Mueller et al., 2008). The reliability among the current sample was satisfactory $(\alpha=.69)$.

\section{Data Analysis}

The analytic plan for the current study contained three elements. First, estimates of probable diagnosis of $I C D-11$ PTSD were computed for $\mathrm{T} 1$ and $\mathrm{T} 2$. Second, the factorial validity of $I C D$ 11 PTSD was assessed using CFA techniques. This involved a comparison of three models: Model 1, a correlated 3-factor model (two items loading onto reexperiencing, avoidance, and sense of threat, respectively) consistent with the ICD-11 proposals; Model 2, a correlated 2-factor model identified by Forbes et al. (2015) and Haravuori et al. (2016) in which the reexperiencing and avoidance factors are combined into a single factor; and Model 3, a unidimensional model in which the six items load onto a single PTSD factor. This analysis was based on T1 data (1994) and conducted using Mplus 7.00 (Muthén \& Muthén, 2013; it was not possible to assess the latent structure at T2 given the limited sample size). The weighted least square mean- and variance-adjusted estimator (Beauducel \& Herzberg, 2006) was used for CFA. Standard procedures for determining model fit were followed (Kline, 2011), whereby 
excellent fit was indicated by a nonsignificant chi-square value; comparative fit index (CFI) and Tucker-Lewis index (TLI) values > .95; and a root mean square error of approximation (RMSEA) with $90 \%$ confidence interval $(\mathrm{CI})$ values $<.06$. Furthermore, the Bayesian information criterion (BIC) was used to evaluate alternative models, with the smallest value indicating the best-fitting model (the robust maximum likelihood estimator was used to generate BIC values for the purposes of model comparison). A 10-point difference between two BIC values is suggested to represent strong evidence (odds ratio $=150: 1)$ that the model with the lower value is superior (Raferty, 1995).

Third, hierarchical multiple regression analysis was conducted to assess the ability of the constituent elements of ICD-11 PTSD, measured in 1994, to predict seven outcome variables (depression, quality of life, internalized anger, externalized anger, hatred for perpetrators, dysfunctional disclosure, and social acknowledgment as a victim) 15 years later in 20082009. For all outcome variables, sex was entered into the regression model at Step 1 and summed scores of reexperiencing, avoidance, and sense of threat were entered at Step 2. Analyses were conducted in SPSS version 23.

\section{Results}

Descriptive statistics of the PTSD symptom clusters and total scores from $\mathrm{T} 1$ and $\mathrm{T} 2$ are reported in Table 2. Based on the symptom criteria requirements for diagnosis of $I C D-11$ PTSD, $48.2 \%(n=66)$ of the sample at T1 met the diagnostic criteria, and $42.5 \%(n=37)$ met the diagnostic criteria at T2. When functional impairment was included at T2, $37.2 \%(n=32)$ of the sample met diagnostic criteria, a nonstatistically significant change in prevalence $(z=0.77, p=$ .224). At $\mathrm{T} 1$ and $\mathrm{T} 2$, reexperiencing was the most commonly endorsed symptom cluster, followed by sense of threat and avoidance.

Among those participants available at follow-up, $22.0 \%$ $(n=18)$ met the $I C D-11$ PTSD symptom diagnostic criteria at $\mathrm{T} 1$ and $\mathrm{T} 2 ; 17.1 \%(n=14)$ met diagnostic criteria at $\mathrm{T} 1$ and did not meet diagnostic criteria at T2; 19.5\% $(n=16)$ did not meet diagnostic criteria at $\mathrm{T} 1$ and did meet diagnostic criteria at T2; and $41.5 \%(n=34)$ did not meet diagnostic criteria at $\mathrm{T} 1$ and $\mathrm{T} 2$.

The CFA findings supported the factorial validity of the proposed ICD-11 model of PTSD. The correlated 3-factor model demonstrated excellent fit across all indices, $\chi^{2}=1.78$, degrees of freedom $(d f)=6, p \equiv .94, \mathrm{CFI}=1.00$, TLI $=1.02$, RMSEA $=.00,90 \% \mathrm{CI}[0.00,0.03], \mathrm{BIC}=2348.77$; and was superior to the 2 -factor model, $\chi^{2}=26.09, d f=8, p=.001, \mathrm{CFI}=$ $.96, \mathrm{TLI}=.93, \mathrm{RMSEA}=.13,90 \%$ CI $[0.08,0.18], \mathrm{BIC}=$ 2363.17; and the unidimensional model, $\chi^{2}=29.27, d f=9$, $p<.001, \mathrm{CFI}=.96, \mathrm{TLI}=.93, \mathrm{RMSEA}=.13,90 \% \mathrm{CI}[0.08$, $0.18], \mathrm{BIC}=2359.34$. Additionally, each item loaded onto its respective factor positively and strongly, and the three factors were moderate-to-highly correlated (Table 3 ).
Table 4 includes the results of a series of hierarchical multiple linear regression analyses. Seven outcome variables were assessed (depression, quality of life, internalized anger, externalized anger, hatred of perpetrators, problems in disclosure, and social acknowledgment as a victim). In each case, sex was entered at Step 1 and the PTSD symptom clusters (reexperiencing, avoidance, and sense of threat) were entered at Step 2. Preliminary analyses revealed no serious violations of the assumptions of multicollinearity, homoscedasticity, linearity, and normality.

At Step 1 of the analyses sex significantly contributed to the explanation of depression, $F(1,79)=11.01, p=.001$, $R^{2}=.12$; quality of life, $F(1,78)=13.22, p<.001, R^{2}=$ .15 ; and dysfunctional disclosure, $F(1,78)=10.49, p=.002$, $R^{2}=.12$. The introduction of the ICD-11 PTSD symptom clusters significantly contributed a meaningful percentage of variance to all seven outcomes. The largest unique explanatory effect was observed for dysfunctional disclosure, $\Delta R^{2}=$ $.27, F(3,75)=10.93, p<.001$; followed by quality of life, $\Delta R^{2}=.21, F(3,75)=7.97, p<.001 ;$ depression, $\Delta R^{2}=.17$, $F(3,76)=6.19, p=.001$; hatred of perpetrators, $\Delta R^{2}=.15$, $F(3,76)=4.65, p=.005$; social acknowledgment as a victim, $\Delta R^{2}=.12, F(3,75)=3.50, p=.019$; externalized anger, $\Delta R^{2}=.14, F(3,76)=3.43, p=.021 ;$ and internalized anger, $\Delta R^{2}=.10, F(3,75)=2.80, p=.046$.

In the final model, increased levels of Th significantly predicted decreased levels of quality of life $(\beta=-.42, p=.002)$, increased levels of social acknowledgment $(\beta=.33, p=.028)$, and increased levels of depression $(\beta=.29, p=.031)$. The avoidance symptoms significantly predicted increased levels of internalized anger $(\beta=.30, p=.032)$ and dysfunctional disclosure $(\beta=.25, p=.031)$. Finally, although Re did not predict any of the outcome variables to a statistically significant degree, the observed positive, predictive effect on feelings of hatred for one's perpetrator was of such a magnitude that it warrants consideration as a potentially meaningful effect $(\beta=.24, p=.071)$.

\section{Discussion}

This study sought to evaluate the possibility of using the welltried IES-R to estimate the new ICD-11 PTSD definition, and to subsequently assess its ability to prospectively predict a range of trauma-relevant outcomes. Data from a comprehensive 15-year longitudinal study on former political prisoners from communist East Germany supported the general applicability of the new ICD-11 PTSD definition. The two items included from each of the three symptom groups (reexperiencing, avoidance, and sense of threat) showed satisfactory model fit and meaningful predictive patterns.

Based on the IES-R, a substantial proportion of the sample met probable PTSD diagnosis at both assessment periods. The absence of a measure of functional impairment within the IES-R may be considered one of the scale's primary limitations as a method of capturing the ICD-11 PTSD profile 
Table 2

Descriptive Statistics and Percentage of Sample Meeting Symptom Criteria for ICD-11 PTSD

\begin{tabular}{|c|c|c|c|c|c|c|}
\hline PTSD symptom cluster & $\begin{array}{c}\text { Participants meeting } \\
\text { diagnostic symptom } \\
\text { criteria (\%) }\end{array}$ & $M$ & $95 \% \mathrm{CI}$ & $M d n$ & $S D$ & Range \\
\hline \multicolumn{7}{|l|}{ Time 1-1994 } \\
\hline Reexperiencing & 81.7 & 5.73 & {$[5.41,6.05]$} & 6 & 1.86 & $2-8$ \\
\hline Avoidance & 55.1 & 4.43 & {$[4.08,4.77]$} & 5 & 2.04 & $2-8$ \\
\hline Sense of threat & 73.9 & 5.41 & {$[5.06,5.75]$} & 6 & 2.00 & $2-8$ \\
\hline$I C D-11$ PTSD & 48.2 & 15.60 & {$[14.76,16.43]$} & 16 & 4.87 & $6-24$ \\
\hline \multicolumn{7}{|l|}{ Time 2-2008-2009 } \\
\hline Reexperiencing & 73.9 & 5.45 & {$[5.06,5.89]$} & 6 & 1.96 & $2-8$ \\
\hline Avoidance & 56.3 & 4.60 & {$[4.15,5.05]$} & 4 & 2.12 & $2-8$ \\
\hline Sense of threat & 68.2 & 5.09 & {$[4.67,5.51$} & 5 & 1.98 & $2-8$ \\
\hline$I C D-11$ PTSD & $42.5(36.8)^{\mathrm{a}}$ & 15.17 & {$[14.10,16.24]$} & 15 & 5.05 & $6-24$ \\
\hline
\end{tabular}

Note. $N=144$ at Time $1 ; N=88$ at Time 2. ICD-11 PTSD = International Classification of Diseases, 11 th ed. model of posttraumatic stress disorder; $95 \%$ CI $=95 \%$ confidence intervals for the mean.

a Diagnostic rates at Time 2 with the functional impairment criteria included are presented in parentheses.

Table 3

Standardized Factor Loadings and Associated Standard Errors, and Factor Correlations and Associated Standard Errors for ICD-11 PTSD at Time 1

\begin{tabular}{|c|c|c|c|c|c|c|}
\hline Symptom & $\operatorname{Re}$ & SE & Av & SE & Th & SE \\
\hline \multicolumn{7}{|l|}{ Factor loadings } \\
\hline Nightmares (IES-R 20) & .79 & .07 & & & & \\
\hline Reliving the trauma (IES-R 9) & .76 & .08 & & & & \\
\hline Avoidance of internal reminders (IES-R 11) & & & .90 & .05 & & \\
\hline Avoidance of external reminders (IES-R 8) & & & .76 & .06 & & \\
\hline Hypervigilance (IES-R 21) & & & & & .73 & .07 \\
\hline Exaggerated startle response (IES-R 10) & & & & & .83 & .06 \\
\hline \multicolumn{6}{|l|}{ Factor correlations } & \\
\hline Reexperiencing & 1.00 & & & & & \\
\hline Avoidance & .62 & .09 & 1.00 & & & \\
\hline Sense of threat & .83 & .08 & .80 & .07 & 1.00 & \\
\hline
\end{tabular}

Note. All results are statistically significant $(p<.001)$. ICD-11 = International Classification of Diseases, 11th ed.; IES-R = Impact of Event Scale-Revised; SE $=$ standard error; $\mathrm{Re}=$ reexperiencing; $\mathrm{Av}=$ avoidance; $\mathrm{Th}=$ sense of threat.

given that findings tend to indicate that omission of functional impairment can inflate diagnostic rates (e.g., Wisco et al., 2016). Despite this general trend in the literature, the introduction of functional impairment at the follow-up assessment did not lead to a statistically significant decline in the proportion of individuals meeting caseness for PTSD. In a previous study based on the same sample, Maercker, Gabler, et al. (2013) reported PTSD rates of $33.3 \%$ at $\mathrm{T} 1$ and $29.2 \%$ at $\mathrm{T} 2$ according to a diagnostic interview for the Diagnostic and Statistical Manual of Mental Disorders (4th ed., DSM-IV; American Psychiatric Association, 1994). It is possible therefore that the diagnostic rates generated by the IES-R are an overestimation of the true rates of PTSD. Although the distinct symptom profiles of $I C D-11$ and $D S M-I V$ can lead to discrepant diagnostic rates, the trend has been for the $I C D-11$ to produce lower, not higher, estimates than the DSM-IV (O'Donnell et al., 2014; Stammel et al., 2015). The elevated rates of probable PTSD based on the IES-R are thus more likely the result of the well-demonstrated trend for self-report measures to generate modestly higher levels of diagnosis compared to diagnostic interviews (e.g., Griffin, Uhlmansiek, Resick, \& Mechanic, 2004).

The results of the CFA analyses supported the latent symptom structure of PTSD as proposed by the ICD-11. The 3-factor model was found to provide an excellent representation of the current sample data and adds to a growing body of evidence drawn from diverse trauma and cultural samples supporting the factorial validity of ICD-11 PTSD (Forbes et al., 2015; Gluck et al., 2016; Hansen et al., 2015; Tay et al., 2015). Current 


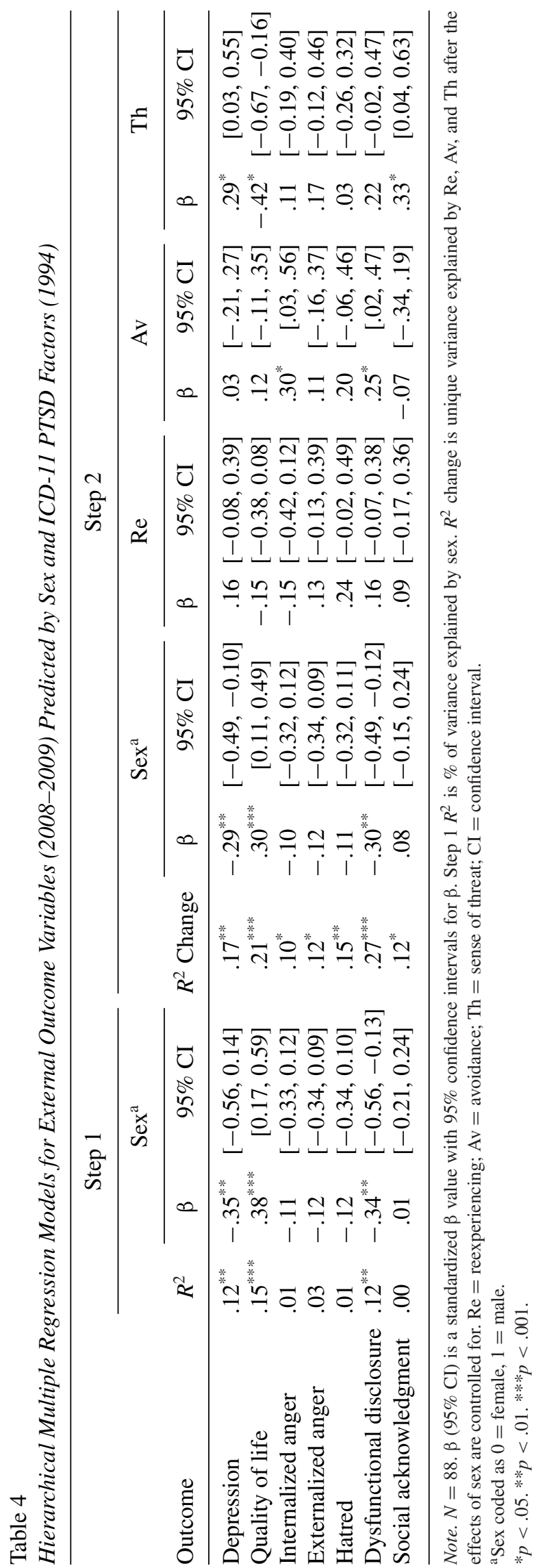

findings suggest that the widely used IES-R is a viable method of mapping the $I C D-11$ model of PTSD for research purposes. Given that self-report and diagnostic interview measures specifically designed for $I C D-11$ PTSD are currently under development, the IES-R offers researchers engaged in trauma research a feasible method of integrating $I C D-11$ proposals for PTSD into ongoing research efforts.

In addition to providing further evidence of the factorial validity of $I C D-11$ PTSD, the current study provides the first piece of empirical evidence regarding the predictive validity of the model. Independent of sex, depression and quality of life at the 15-year follow-up were robustly predicted by the ICD-11 PTSD factors, with a particularly strong contribution from the sense of threat symptoms. Trauma-related interpersonal consequences (social acknowledgment and disclosure) and social affects (anger and hatred) were meaningfully predicted by the PTSD symptoms, the former to a greater extent than the latter. Dysfunctional disclosure (reluctance to disclose and strong emotional reactivity while disclosing) was positively predicted by avoidance symptoms 15 years earlier. Disclosure of traumatic experiences contributes to short-term recovery from PTSD (Mueller et al., 2008), and current findings suggest that over the longer term, recovery may also be impeded by high levels of initial avoidance, mediated by lack of disclosure. Threat symptoms specifically predicted current self-perceived social acknowledgment as a survivor. In Germany and other former communist countries in Eastern Europe, many former political prisoners of the totalitarian regime still feel unacknowledged (Kazlauskas \& Zelviene, 2016). Current results indicate that their ongoing sense of threat may have a substantial social component and not only consists of reactions towards situational or other contextual triggers.

This study contained several limitations. First, despite the unique nature of the sample, the sample size was small; consequently, the generalizability of these findings is limited. It was not possible to assess the factorial validity of $I C D-11$ PTSD at T2 given the limited sample that remained; however, Monte Carlo simulation studies of sample size requirements for CFA indicate that the available sample size at $\mathrm{T} 1$ was sufficient to reliably undertake the CFA procedures (Wolf, Harrington, Clark, \& Miller, 2013). Although it was possible to control for sex in the regression analyses, the reduced sample size prevented the inclusion of additional covariates that are likely important. Age and educational status was associated with attrition from T1 to T2; therefore, the omission of these covariates may have influenced the results. Future studies evaluating $I C D-11$ PTSD would benefit from the inclusion of additional covariates to provide a more robust assessment of the predictive validity of the model.

There are three limitations associated with using the IES-R to model $I C D-11$ PTSD. First, and as previously mentioned, the IES-R does not contain a measure of functional impairment, which is a criterion for ICD-11 PTSD diagnosis. Second, the ICD-11 model of PTSD emphasizes that reexperiencing of the trauma must occur in the "here and now" so as to distinguish 
these symptoms from similar symptoms observed in other clinical disorders such as depression (Brewin, 2015). The inclusion of present-moment reexperiencing is emphasised as empirical findings indicate that this type of reexperiencing can discriminate trauma-exposed individuals who will develop PTSD from those who will not (Brewin, 2015; Reynolds \& Brewin, 1998). The IES-R items used to capture reexperiencing do not include a "here and now" component, and this may also have contributed to the higher diagnostic estimates. Third, the IES-R enquires about trauma symptoms experienced over the past 7 days, whereas the $I C D-11$ requires that these distressing symptoms be present for several weeks.

The value of the IES-R as a measure capable of capturing the $I C D-11$ diagnosis of PTSD should be considered with these limitations in mind. The $I C D-11$ model of PTSD is distinguishable from the $D S M$-based models in terms of both structure (a correlated 3-factor structure based on six or seven symptoms) and content (unique symptoms that emphasize present-moment reexperiencing and a heightened sense of current threat, over a given period). The IES-R appears to perform well with respect to representing the $I C D-11$ PTSD structure, but there are deficiencies with its ability to capture the $I C D-11$ PTSD content. In the absence of a specifically designed and psychometrically validated self-report measure of ICD-11 PTSD (the development and validation of specific ICD-11 PTSD self-report and clinician-administered scales is ongoing), the IES-R can be regarded as a useful method of capturing the ICD-11 PTSD structure for research purposes. In conclusion, current findings provide additional support for the basic factorial validity of ICD-11 PTSD among a unique sample of trauma victims, and offer initial evidence of the predictive validity of the construct.

\section{References}

American Psychiatric Association. (1994). Diagnostic and statistical manual of mental disorders ( $4^{\text {th }}$ ed.). Washington, DC: Author.

American Psychiatric Association. (2013). Diagnostic and statistical manual of mental disorders ( $5^{\text {th }}$ ed.). Arlington, VA: American Psychiatric Association.

Beauducel, A., \& Herzberg, P. Y. (2006). On the performance of maximum likelihood versus means and variance adjusted weighted least squares estimation in CFA. Structural Equation Modeling, 13, 186-203. doi: $10.1207 / \mathrm{s} 15328007 \mathrm{sem} 1302 \_2$

Bech, P. (2004). Measuring the dimension of psychological general well-being by the WHO-5. Quality of Life Newsletter, 32, 15-16.

Beck, A. T., Steer, R. A., \& Carbin, M. G. (1988). Psychometric properties of the Beck Depression Inventory: Twenty-five years of evaluation. Clinical Psychology Review, 8, 77-100. doi:10.1016/0272-7358(88)90050-5

Bisson, J. I. (2013). What happened to harmonization of the PTSD diagnosis? The divergence of ICD11 and DSM5. Epidemiology and Psychiatric Sciences, 22, 205-207. doi:10.1017/S2045796013000164

Brewin, C. R. (2015). Re-experiencing traumatic events in PTSD: New avenues in research on intrusive memories and flashbacks. European Journal of Psychotraumatology, 6, 27180. doi:10.3402/ejpt.v6.27180

Brewin, C. R., Lanius, R. A., Novac, A., Schnyder, U., \& Galea, S. (2009). Reformulating PTSD for DSMV: Life after Criterion A. Journal of Traumatic Stress, 22, 366-373. doi:10.1002/jts.20443
Elklit, A., \& Shevlin, M. (2007). The structure of PTSD symptoms: A test of alternative models using confirmatory factor analysis. British Journal of Clinical Psychology, 46, 299-313. doi:10.1348/014466506X171540

First, M. B., Reed, G. M., Hyman, S. E., \& Saxena, S. (2015). The development of the $I C D-11$ clinical descriptions and diagnostic guideline for mental and behavioural disorders. World Psychiatry, 14, 82-90. doi:10.1002/wps.20189

Forbes, D., Lockwood, E., Creamer, M., Bryant, R. A., McFarlane, A C., Silove, D., ... O'Donnell, M. (2015). Latent structure of the proposed $I C D-11$ post-traumatic stress disorder symptoms: Implications for the diagnostic algorithm. British Journal of Psychiatry, 206, 245-251. doi:10.1192/bjp.bp.114.150078

Gluck, T. M., Knefel, M., Tran, U. S., \& Lueger-Schuster, B. (2016). PTSD in $I C D-10$ and proposed $I C D-11$ in elderly with childhood trauma: Prevalence, factor structure, and symptom profiles. European Journal of Psychotraumatology, 7, 29700. doi:10.3402/ejpt.v7.29700

Griffin, M. G., Uhlmansiek, M. H., Resick, P. A., \& Mechanic, M. B. (2004). Comparison of the Posttraumatic Stress Disorder Scale versus the Clinician-Administered Posttraumatic Stress Disorder Scale in domestic violence survivors. Journal of Traumatic Stress, 17, 497-503. doi:10.1007/s10960-004-5798-4

Hansen, M., Hyland, P., Armour, C., Elklit, A., \& Shevlin, M. (2015). Less is more? Assessing the validity of the ICD-11 model of PTSD across multiple trauma samples. European Journal of Psychotraumatology, 6, 28766. doi:10.3402/ejpt.v6.28766

Haravuori, H., Kiviruusu, O., Suomalainen, L., \& Marttunen, M. (2016). An evaluation of $I C D-11$ posttraumatic stress disorder criteria in two samples of adolescents and young adults exposed to mass shootings: Factor analysis and comparisons to ICD-10 and DSM-IV. BMC Psychiatry, 16, 140. doi:10.1186/s12888-016-0849-y

Herberman Mash, H. B., Ursano, R. J., Benevides, K. N., \& Fullerton, C. S (2016). Identification with terrorist victims of the Washington, DC sniper attacks: Posttraumatic stress and depression. Journal of Traumatic Stress, 29, 41-48. doi:10.1002/jts.22069

Horowitz, M. J. (1976). Stress response syndromes. New York: Jason Aronson.

Kazlauskas, E., \& Zelviene, P. (2016). Trauma research in the Baltic countries: From political oppression to recovery. European Journal of Psychotraumatology, 7, 29295. doi:10.3402/ejpt.v7.29295

Kline, R. B. (2011). Principles and practice of structural equation modeling ( $3^{\text {rd }}$ ed.). London, England: Guilford Press.

Lopes Cardozo, B., Kaiser, R., Gotway, C. A., \& Agani, F. (2003). Mental health, social functioning, and feelings of hatred and revenge of Kosovar Albanians one year after the war in Kosovo. Journal of Traumatic Stress, 16,351-360. doi:10.1023/A:1024413918346

Maercker, A., Brewin, C. R., Bryant, R. A., Cloitre, M., Ommeren, M., Jones, L. M., ... Somasundaram, D. J. (2013). Diagnosis and classification of disorders specifically associated with stress: Proposals for $I C D-11$. World Psychiatry, 12, 198-206. doi:10.1002/wps.20057

Maercker, A., Gäbler, I., O’Neil, J., Schützwohl, M., \& Müller, M. (2013). Long-term trajectories of PTSD or resilience in former East German political prisoners. Torture, 23, 15-27.

Maercker, A., \& Horn, A. B. (2013). A socio-interpersonal perspective on PTSD: The case for environments and interpersonal processes. Clinical Psychology \& Psychotherapy, 20, 465-481. doi:10.1002/cpp.1805

Maercker, A., \& Müller, J. (2004). Social acknowledgment as a victim or survivor: A scale to measure a recovery factor of PTSD. Journal of Traumatic Stress, 17, 345-351. doi:10.1023/B:JOTS.0000038484.15488.3d

Maercker, A., \& Schützwohl, M. (1998). Erfassung von psychischen Belastungsfolgen: Die Impact of Event Skala-revidierte Version (IES-R) 
[Detection of psychological stress: The impact of Event Scale-revised version]. Diagnostica, 44, 130-141.

Morina, N., van Emmerik, A. A. P., Andrews, B., \& Brewin, C. R. (2014). Comparison of $D S M-I V$ and proposed $I C D$ - 11 formulations of PTSD among civilian survivors of war and war veterans. Journal of Traumatic Stress, 27, 674-654. doi:10.1002/jts.21969

Müller, J., \& Maercker, A. (2006). Disclosure und wahrgenommene gesellschaftliche wertschätzung als opfer als prädiktoren von ptb bei kriminalitätsopfern [Disclosure and perceived acknowledgment as victim in crime victims]. Zeitschrift für klinische Psychologie und Psychotherapie, 35, $49-58$.

Mueller, J., Moergeli, H., \& Maercker, A. (2008). Disclosure and social acknowledgement as predictors of recovery from posttraumatic stress: A longitudinal study in crime victims. Canadian Journal of Psychiatry, 53, 160-168.

Muthén, L. K., \& Muthén, B. O. (2013). MPlus user's guide (7th ed.). Los Angeles, CA: Author.

O’Donnell, M. L., Alkemade, N., Nickerson, A., Creamer, M., McFarlane, A C., ... Forbes, D. (2014). Impact of the diagnostic changes to post-traumatic stress disorder for DSM-5 and the proposed changes to ICD-11. British Journal of Psychiatry, 205, 230-235. doi:10.1192/bjp.bp.113.135285

Orth, U., Maercker, A., \& Montada, L. (2003). Rachegefühle und posttraumatische belastungsreaktionen bei opfern von gewalttaten [Feelings of revenge and PTSD in victims of violence]. Zeitschrift für Klinische Psychologie und Psychotherapie, 32, 169-175.

Raftery, A. E. (1995). Bayesian model selection in social research. Sociological Methodology, 25, 111-163. doi:10.2307/271063

Reynolds, M., \& Brewin, C. R. (1998). Intrusive cognitions, coping strategies and emotional responses in depression, post-traumatic stress disorder and a non-clinical population. Behaviour Research and Therapy, 36, 135-147. doi:10.1016/s0005-7967(98)00013-8.

Schneider, S., \& Margraf, J. (2006). DIPS-Diagnostisches Interview bei Psychischen Störungen [Diagnostic Interview for Mental Disorders] ( $3^{\text {rd }}$ ed.). Göttingen, Germany: Hogrefe.

Schnurr, P. P., \& Lunney, C. A. (2016). Symptom benchmarks or improved quality of life in PTSD. Depression \& Anxiety, 33, 247-255. doi:10.1002/da.22477
Schwenkmezger, P., Hodapp, V., \& Spielberger, C. D. (1992). State-TraitÄrger-Aus-Drucksinventar STAXI [State-Trait Anger Expression Inventory STAXI]. Bern, Switzerland: Huber.

Stammel, N., Abbing, E. M., Heeke, C., \& Knaevelsrud, C. (2015). Applicability of the ICD-11 proposal for PTSD: A comparison of prevalence and comorbidity rates with the DSM-IV PTSD classification in two post-conflict samples. European Journal of Psychotraumatology, 6, 27070. doi:10.3402/ejpt.v6.27070

Stander, V. A., Thomsen, C. J., \& Highfill-McRoy, R. M. (2014). Etiology of depression comorbidity in combat-related PTSD: A review of the literature. Clinical Psychology Review, 34, 87-98. doi:10.1016/j.cpr.2013.12. 002

Tay, A. K., Rees, S., Chen, J., Kareth, M., \& Silove, D. (2015). The structure of post-traumatic stress disorder and complex post-traumatic stress disorder amongst West Papuan refugees. BMC Psychiatry, 15, 111. doi:10.1186/s12888-015-0480-3

Thormar, S. B., Sijbrandij, M., Gersons, B. P., de Schoot, R., Juen, B., Karlsson, T., \& Olff, M. (2016). PTSD symptom trajectories in disaster volunteers: The role of self-efficacy, social acknowledgement, and tasks carried out Journal of Traumatic Stress, 29, 17-25. doi:10.1002/jts.22073.

Topp, C. W., Østergaard, S. D., Søndergaard, S., \& Bech, P. (2015). The WHO5 Well-Being Index: A systematic review of the literature. Psychotherapy and Psychosomatics, 84, 167-176. doi:10.1159/000376585

Weiss, D. S., \& Marmar, C. R. (1996). The Impact of Event Scale-Revised. In J. Wilson \& T. M. Keane (Eds.), Assessing psychological trauma and PTSD (pp. 399-411). New York, NY: Guilford Press.

Wisco, B. E., Miller, M. W., Wolf, E. J., Kilpatrick, D., Resnick, H. S., Badour, C. L., ... Friedman, M. J. (2016). The impact of proposed changes to $I C D$ 11 on estimates of PTSD prevalence and comorbidity. Psychiatry Research, 240, 226-233. doi:10.1016/j.psychres.2016.04.043

Wolf, E. J., Harrington, K. M., Clark, S. L., \& Miller, M. W. (2013). Sample size requirements for structural equation models: An evaluation of power, bias, and solution propriety. Educational and Psychological Measurement, 76, 913-934. doi:10.1177/0013164413495237

World Health Organization. (2017). International classification of diseases (11th ed.). Manuscript in preparation. 